\title{
OVERCOMING THE CHALLENGES OF COLLABORATIVELY ADOPTING ARTIFICIAL INTELLIGENCE IN THE PUBLIC SECTOR
}

Averill Campion (ESADE - Ramon Llull University), Mila Gasco-Hernandez (Rockefeller College of Public Affairs \& Policy and CTG UAlbany, University at Albany-SUNY), Slava Jankin Mikhaylov (Hertie School), Marc Esteve (University College London and ESADE Ramon Llull University)

\begin{abstract}
Despite their current popularity and the steady increase in the number of articles published over time, research on artificial intelligence (AI) in public contexts is still scarce, and assumptions on the drivers, challenges, and impacts of AI in government are still far from conclusive. By using a case study that involves a large research university in England and two different county councils in a multi-year collaborative project around AI, we study the challenges of interorganizational collaborations in the adoption of $\mathrm{AI}$ tools and the implementation of organizational routines used to address them. Our results show that resistance to share the data, which is the consequence of privacy/security concerns, a lack of understanding of what data was available/needed, a lack of alignment between project interests and expectations around data sharing, and a lack of engagement throughout the organizational hierarchy, are the most important challenges. Further, organizational routines to overcome challenges include working on-site, showing the benefits of data sharing, re-framing problems, designating joint appointments and boundary spanners, and connecting all levels of collaborative participants around project design and purpose.
\end{abstract}

\section{KEYWORDS}

Adoption of AI, challenges of AI, organizational routines, interorganizational collaboration 


\section{OVERCOMING THE CHALLENGES OF COLLABORATIVELY ADOPTING ARTIFICIAL INTELLIGENCE IN THE PUBLIC SECTOR}

\section{INTRODUCTION}

The European Commission (2019, p.1) defines artificial intelligence (AI) as "systems that display intelligent behavior by analyzing their environment and taking actions - with some degree of autonomy - to achieve specific goals.” As a scientific discipline, AI includes several techniques like machine learning (with deep learning and reinforcement learning as specific examples), machine reasoning, and robotics (European Commission, 2019). However, much of what is discussed as $\mathrm{AI}$ in the public sphere is machine learning (ML), which is an "algorithmic field that blends ideas from statistics, computer science and many other disciplines [...] to design algorithms that process data, make predictions, and help make decisions" (Jordan, 2019). ML has a history of successful deployment in both industry and academia going back several decades. Deep learning has more recently made great progress in such applications as speech and language understanding, computer vision, and event and behavior prediction. These rapid technological advances hold the promise of automation and "human intelligence augmentation" for organizations (Jordan, 2019).

AI technologies are currently experiencing a surge in diffusion and adoption by public organizations. Despite their current popularity and the steady increase in the number of articles published over time, research on AI in public contexts is still scarce, and assumptions on the drivers, challenges, and impacts of AI in government are still far from conclusive (Gomes de Sousa et al., 2019). 
In general, scholarly work on $\mathrm{AI}$ in the public sector has predominantly addressed public sector use of AI in government functions related to general public services, economic affairs, and environmental protection in which $\mathrm{AI}$ techniques, such as machine learning, are used most frequently (Gomes de Sousa et al., 2019). Research is only beginning to identify the manifold challenges faced in the adoption of $\mathrm{AI}$ in the public sector. The few existing studies on this topic have mainly focused on the perils of AI, such as those related to its negative impact on the workforce, the required balance between privacy and data acquisition, and regulatory environment, as well as on the resulting political and ethical implications of AI (Wirtz et al., 2019). However, there is still need for research that specifically addresses the challenges that organizations face when adopting AI, driven by, among others, scarcity of resources, technical capacity and capability, and organizational path dependency (Mikhaylov et al., 2018). In addition, AI adoption often requires the use of interorganizational collaboration to more effectively orchestrate the benefits of AI through combining different competencies and capacities of partners for public service delivery or program and policy evaluation. However, although there is extensive research on interorganizational collaboration to date, few studies have examined AI based initiatives.

This article aims to contribute to bridging this gap by studying the challenges of interorganizational collaborations in the adoption of AI tools and the implementation of organizational routines used to address those challenges. Therefore, our research questions are: 1) what are the challenges of interorganizational collaboration in the adoption of AI? and 2) what organizational routines do managers perform to overcome those challenges? For the purposes of this study, we build on the European Commission (2019) and Jordan (2019) and adopt an operational definition of $\mathrm{AI}$ in the public sector as a set of technologies, solutions and processes 
designed to augment policymakers' decision making by utilizing machine learning and big administrative data. Further, we understand adoption as a process that entails two stages: development (conceiving, scoping, and building) and adoption (testing) (Kim \& Crowston, 2012). Finally, we define organizational routines as "patterns that participants use to guide, account for and refer to specific performances of a routine" (Pentland \& Feldman, 2005, p. 795) and that aim to produce "repetitive, recognizable patterns of interdependent actions, carried out by multiple actors" (Feldman \& Pentland, 2003, p. 95).

\section{THE CHALLENGES OF AI IN THE PUBLIC SECTOR}

Although there is still little research into artificial intelligence in the public sector, a small collection of literature consisting of scholarly studies and several practitioner-oriented reports shows a growing interest in this topic. Generally speaking, these works present the benefits of AI applications for public services across many domains of government, but also recognize that the potential of AI is impaired by a number of technical, organizational, and policy challenges (Kankanhalli et al., 2019).

Dwivedi et al. (2019) and Sun and Medaglia (2019) classify these challenges according to seven categories: 1) social challenges, 2) economic challenges, 3) technological challenges, 4) data challenges, 5) organizational and managerial challenges, 6) ethical challenges, and 7) political, legal, and policy challenges. Social challenges include issues related to existing societal norms and attitudes towards the adoption of AI in government. They may include unrealistic expectations towards AI technology, a societal misunderstanding of the capabilities of AI technologies, potential job losses, and increasing inequality (Sun \& Medaglia, 2019; Dwivedi et al., 2019; Risse, 2019; Korinek \& Stiglitz, 2017). Economic challenges include obstacles 
concerning profitability and economic sustainability and, therefore, have to do with the costs and investments associated with the adoption of AI by public organizations. Wirtz et al. (2019) state that financial feasibility is actually one of the biggest challenges organizations face when initiating AI programs and particularly refer to two main cost drivers that make financial feasibility a major challenge in the context of implementation: the necessary investment in technology and the high demand for a limited number of AI experts, which is associated with increasing costs of education and salaries.

Challenges may also be technological, that is, related to the nature and characteristics of AI technologies. In their study of AI in healthcare, Sun and Medaglia (2019) identify two technological challenges: the lack of transparency of AI algorithms, which matters given that algorithms are responsible for transforming data inputs into concrete decisions, and the difficulties of AI systems in processing unstructured data. Further, Dwivedi et al. (2019) discuss the limitations of AI tools in understanding the situations humans experience and deriving the right meaning from it. For Kankanhalli et al. (2019), given that the infrastructure of AI tools is comprised of several key elements that involve different technologies, how these technologies work with each other becomes a key issue. The authors, therefore, state that the interoperability of AI systems is also an important technological challenge: the lack of technical standards in the AI industry results in variations in hardware and software, which "leads to an inconsistent technology ecosystem, which causes interoperability issues. Further, the system may not be interoperable with other government applications" (p. 305).

Since AI applications are heavily data-dependent, challenges associated with the data have been addressed by several studies. Sun \& Medaglia (2019) discuss the insufficient size of the available database, the absence of data standards, referring to what and how data is collected, 
and what format it is stored in, as well as the difficulties of data integration. The latter has particularly been addressed by previous literature. As the data of AI systems not only derives from multiple channels but also from different sources, sharing and integrating data among government agencies and departments and external stakeholders remains a perpetual challenge (Christodoulou et al., 2018). Technological challenges do also impact the degree of data integration. Desouza (2018) explains that the siloed nature of IT systems in the public sector as well as the misalignment of agency-specific IT and data governance protocols result in difficulties to integrate data across systems on key thematic issues. In sum, the lack of interoperability "limits how agencies can integrate multiple databases that machine learning algorithms can then analyze and use to provide richer insights" (p. 22). Data privacy and security are two additional interrelated data challenges, since problems with data security may also threaten data privacy (Kankanhalli et al., 2019): the use of AI in the public sector may entail the risk of massive surveillance and loss of privacy as well as may encourage malicious attacks targeting access and abuse of these data (Wirtz et al., 2019; Wirtz \& Müller, 2019; Dwivedi et al., 2019; Agarwal, 2018; Krishnamurthy \& Desouza, 2018; Mehr, 2017).

Sun and Medaglia (2019) define organizational and managerial challenges as those related to each organization's strategy, human resources, and management practices in the adoption of AI. In their research about AI adoption in public healthcare, they find three important challenges of this nature. The first one, organizational resistance to share the data, is particularly important because it raises additional issues such as the dilemma about who owns the data or the tension between the need for data integration and the interest of individual organizations. It also shows the importance of trust among stakeholders in the adoption of AI (Dwivedi et al., 2019; Kankanhalli et al., 2019; Mikhaylov et al., 2018). The lack of in-house AI 
talent also represents a great challenge, which is not easy to address given that there are not enough specialists and experts in the job market with relevant skills to support and promote AI development (Wirtz et al., 2019). Last, there are potential challenges posed by AI's threat to replace the workforce, despite such fear may be "nuanced by the fact that AI is framed as not capable of replacing specialized, skilled work" (p. 376). Additional organizational challenges may include the lack of clear leadership (Andrews, 2019), the lack of a strategy regarding adoption of AI (Dwivedi et al., 2019; Sun \& Medaglia, 2019), the lack of AI deployment organizational guidelines, including criteria to standardize the way data is collected and shared (Chen \& Lee, 2017), and the ease of use of AI applications (Dwivedi et al., 2019). Further, Krishnamurthy and Desouza (2018) refer to the importance of cultivating a culture of crossagency collaboration, adopting crowd-centric approaches, and developing collaborative leadership and management support.

Given that AI has ethical considerations that differ from other traditional technologies (Sun \& Medaglia, 2019; Bullock, 2019), research has also paid attention to the impact of AI on moral principles. Among other, previous literature has referred to the general public's lack of trust towards AI-based decisions, the unethical use of the shared data, the (in)compatibility of machine versus human value judgment, and the lack of transparency in the decision-making processes (which may result in bias and lack of fairness) (Freeman et al., 2020; Dwivedi et al., 2019; Sun \& Medaglia, 2019; Kankanhalli et al., 2019; Wirtz et al., 2019; Gomez de Sousa et al., 2019; Desouza, 2018; Mikhaylov et al., 2018; Veale et al., 2018; Janssen \& Kuk, 2016). Privacy concerns, in relation to the disclosure of sensitive information to the public, have also been considered an ethical challenge (Krishnamurthy \& Desouza, 2018). 
Finally, AI adoption may also be hindered by political, legal, and policy challenges, such as obstacles connected to responsibility when errors occur using AI systems, to the use of copyrights, and to the lack of market-wide policy regulations (Dwivedi et al., 2019; Sun \& Medaglia, 2019). In general, and despite the existence of some legislation such as the General Data Protection Regulation (GDPR), which regulates personal data protection and privacy in the European Union, existing research shows that current legal frameworks need significant changes in order to effectively protect and incentivize AI adoption (Dwivedi et al., 2019; Wirtz et al., 2019), therefore encouraging policy-makers to establish AI policies that particularly address legal and ethical challenges, as well as to approve specific regulations for different issues, such as data privacy and security or technical standards (Kankanhalli et al., 2019; Duan et al., 2019; Alberti, 2018; Ishii, 2017).

Given our review above, we can draw three important conclusions. First, despite the rhetoric that AI adoption in the public sector faces important challenges, further research is needed in this direction that moves from speculation to gathering evidence. Second, some of these challenges (and particularly, technological, data-related, and organizational challenges) are not new in the literature. Digital government, knowledge transfer, and collaboration studies have already acknowledged the obstacles of collaboratively adopting technology in the public sector (e.g. Vangen, 2017; Gil-Garcia \& Sayogo, 2016; Cristofoli et al., 2015; Pardo et al., 2012; Yang \& Maxwell, 2011; Willem \& Buelens; 2007; Agranoff, 2006; Raub \& Von Wittich, 2004; Vangen \& Huxham, 2003). Yet, it seems that both the scale and type of data needed in AI projects poses unique challenges that still need to be explored (Desouza \& Jacob, 2017). Third, research has mostly emphasized challenges of AI adoption in the public sector largely ignoring the implementation of organizational routines used to address those challenges. 


\section{RESEARCH DESIGN}

To answer our research questions, we used a case study between a large research university in England and two different regional governments (county councils) involved in a multi-year collaborative project around AI. Case studies show how particular practices are developed in particular organizations and, therefore, help refine theory (Ospina et al., 2018). Although qualitative case studies are usually not representative and therefore their results cannot be generalized, they still allow us to study the research questions in depth while leaving room for unexpected, interesting findings that can form the basis for concrete hypotheses to be tested in future research (Marshall \& Rossman, 2011; Yin, 2013). This is particularly useful when there is little existing research on the topic (Yin, 2013), as is the case here.

Case selection was guided by a combination of convenience and purposeful sampling, a technique, which is especially adequate in the identification, and selection of information-rich cases for the most effective use of limited resources (Patton, 2002). The former played an important role since one of the authors of this article was appointed Chief Scientific Advisor of the collaboration, overseeing the different stages of the project across both councils. Given that purposeful sampling involves identifying and selecting individuals or groups of individuals that are especially knowledgeable about or experienced with the phenomenon of interest (Creswell \& Plano Clark, 2017), we could guarantee availability and interest to participate in our study, which are important determinants of successful purposeful sampling (Bernard, 2017).

\section{The case study}

In 2015, a major research university in England partnered with two county councils to build, test, and deploy a suite of AI tools aimed at improving the councils' policy decisions for 
better prevention and early intervention in education, social care, and crime and security. Several reasons sparked the collaboration, which was funded by the Higher Education Funding Council for England (HEFCE). Although both councils were already using standard data sources to inform strategic decisions, they recognized the potential of innovative AI tools. Yet, they did not have the organizational capacity to develop them internally. Using the expertise and research that existed within the university helped address the lack of AI specialists and knowledge in the councils. Further, involving the university had also an impact in terms of external legitimacy, increasing the public's acceptance of the project. Finally, the collaboration also strengthened the university's relationship with the local communities through its work to increase volunteering opportunities for students.

The partnership included impact evaluation of public services metrics and tools and risk stratification modeling tools based on ML, which resulted in a range of different projects from risk stratification (predictive modelling) platforms and evaluation frameworks for school readiness, domestic abuse to youth homeless, youth-reoffending, and school sustainability. Since the legal framework (a combination of the GDPR and the 2018 UK Data Protection Act) requires different departments responsible for the delivery of specific functions to collect and curate the corresponding data (designated "data controllers" under GDPR and DPA), the development and testing of the tools called for data sharing across collaborating organizations for data processors (under GDPR and DPA designation).

The sharing of data between controllers and processors to enable testing and implementation of AI solutions has proven a complicated process even under the legal frameworks of GDPR and DPA. The councils also differed in their approaches: while council 1 developed the tools in-house and used the university in an advisory role, council 2 co-developed 
the tools with the university, which resulted in intensive data sharing and, therefore, the need for data sharing agreements.

\section{Data and methods}

In-depth semi-structured interviews were conducted to collect data and information during May and June 2018, once the AI tools had already been built and tested in both councils and were ready to be deployed. We interviewed 24 individuals from the three organizations (12 from the university, 8 from council 1, and 4 from council 2), including top level leadership, middle managers and bottom level analysts, academics, and $\mathrm{PhD}$ students. Table 1 provides the detail about the profile of the interviewees:

Table 1. Interviewees' profiles

\begin{tabular}{|c|c|c|}
\hline Organization & Position & Role \\
\hline \multirow[t]{11}{*}{ University } & $\begin{array}{l}\text { Academic Directors of } \\
\text { Program Evaluation }\end{array}$ & Strategic - top management \\
\hline & $\begin{array}{l}\text { Deputy Director of Strategic } \\
\text { Change }\end{array}$ & Strategic - top management \\
\hline & Academic Project Manager & Strategic - top management \\
\hline & $\begin{array}{l}\text { Designer of Collaborative } \\
\text { Project }\end{array}$ & Strategic - top management \\
\hline & Project Instigator & Strategic - top level \\
\hline & $\begin{array}{l}\text { Knowledge Exchange } \\
\text { Manager }\end{array}$ & $\begin{array}{l}\text { Middle management } \\
\text { (decision making role about } \\
\text { specific issues) }\end{array}$ \\
\hline & $\begin{array}{l}\text { Senior Data Development } \\
\text { Manager }\end{array}$ & $\begin{array}{l}\text { Middle management } \\
\text { (decision making role about } \\
\text { specific issues) }\end{array}$ \\
\hline & Initial Project Developer & $\begin{array}{l}\text { Middle management } \\
\text { (decision making role about } \\
\text { specific issues) }\end{array}$ \\
\hline & Research Analyst & $\begin{array}{l}\text { Operational - bottom level } \\
\text { (implementer) }\end{array}$ \\
\hline & PhD Student Analyst & $\begin{array}{l}\text { Operational - bottom level } \\
\text { (implementer) }\end{array}$ \\
\hline & $\begin{array}{l}\text { PhD Student for Program } \\
\text { Evaluation }\end{array}$ & $\begin{array}{l}\text { Operational - bottom level } \\
\text { (implementer) }\end{array}$ \\
\hline
\end{tabular}




\begin{tabular}{|c|c|c|}
\hline & Volunteer Hub Coordinator & $\begin{array}{l}\text { Operational - bottom level } \\
\text { (implementer) }\end{array}$ \\
\hline \multirow[t]{8}{*}{ Council 1} & \begin{tabular}{|l|} 
Director of Strategic \\
Commission and Policy
\end{tabular} & Strategic - top management \\
\hline & Head of Corporate Strategy & Strategic - top management \\
\hline & $\begin{array}{l}\text { Head of Strategy of the } \\
\text { Public Sector Reform Unit }\end{array}$ & Strategic - top management \\
\hline & $\begin{array}{l}\text { Head of Profession, Data and } \\
\text { Analytics }\end{array}$ & Strategic - top management \\
\hline & Program Leader & $\begin{array}{l}\text { Middle management } \\
\text { (decision making role about } \\
\text { specific issues) }\end{array}$ \\
\hline & Senior Project Officer & $\begin{array}{l}\text { Middle management } \\
\text { (decision making role about } \\
\text { specific issues) }\end{array}$ \\
\hline & $\begin{array}{l}\text { Intelligence Manager of the } \\
\text { Adult Social Care Office }\end{array}$ & $\begin{array}{l}\text { Operational - bottom level } \\
\text { (implementer) }\end{array}$ \\
\hline & $\begin{array}{l}\text { Data Science Fellow of the } \\
\text { Senior Organizational } \\
\text { Intelligence Office }\end{array}$ & $\begin{array}{l}\text { Operational - bottom level } \\
\text { (implementer) }\end{array}$ \\
\hline \multirow[t]{4}{*}{ Council 2} & $\begin{array}{l}\text { Head of Knowledge and } \\
\text { Intelligence }\end{array}$ & Strategic - top management \\
\hline & $\begin{array}{l}\text { Head of Service of the } \\
\text { Multiagency Safeguarding } \\
\text { Hub }\end{array}$ & $\begin{array}{l}\text { Middle management } \\
\text { (decision making role about } \\
\text { specific issues) }\end{array}$ \\
\hline & $\begin{array}{l}\text { Assistant Director of the } \\
\text { Children's Commissioning }\end{array}$ & $\begin{array}{l}\text { Middle management } \\
\text { (decision making role about } \\
\text { specific issues) }\end{array}$ \\
\hline & Main Project Link & $\begin{array}{l}\text { Operational - bottom level } \\
\text { (implementer) }\end{array}$ \\
\hline
\end{tabular}

The main themes covered in the interviews included but were not limited to purpose, challenges, organizational routines to overcome challenges, results and benefits of the collaboratively adoption process of AI tools, which took place between 2015 and 2018. Interviews lasted between 30-45 minutes and were recorded and verbatim transcribed. Given our coding strategy (see below), a verbatim record of interviews was beneficial in facilitating data analysis by bringing us closer to our data (Halcomb \& Davidson, 2006). 
We used an inductive-deductive strategy to code the interview data (Charmaz, 2014). This entailed using the incipient literature on AI as well as the more consolidated literatures of digital government, collaboration, and knowledge transfer to code data that matched existing concepts of challenges and routines (i.e. goal clarity, leadership, training, resistance to share the data, etc.) while also remaining open to new codes emerging from the data. After the initial primary coding, secondary coding focused on placing the related codes into larger categories. Finally, themes were identified that captured the analytical reflections from the categories.

\section{FINDINGS}

Based on the interviews, our findings mainly show a predominance of one important challenge: resistance to share the data and transfer knowledge between organizations. Our results indicate that this resistance to share the data is, at the same time, the result of: 1) privacy/security concerns (which are the result of institutional laws/regulations and the way specific organizational cultures cope with privacy and security but, also, of a real threat in terms of security/privacy given the type of data AI deals with), 2) lack of understanding of what data was available/needed, 3) lack of interorganizational alignment between project interests and expectations around data sharing, and 4) lack of engagement within the organizational hierarchy in that expectations at the top level were not the same as those at the bottom level. Our findings further suggest that, despite these challenges, organizational routines emerged to cope and iterate approaches to obtain eventual project success. These organizational routines include: working on-site, showing the benefits of data sharing, re-framing problems, designating joint appointments and boundary spanners, and connecting all levels of collaborative participants around project design and purpose. 


\section{Challenge 1: Privacy and security concerns}

Although data governance (e.g. privacy) and cybersecurity (e.g. security) concerns were present in both councils, they manifested differently in each of them, depending on their organizational culture and their legal units' different interpretations of DPA/GDPR requirements. This, in turn, resulted in resistance to share data in both councils; yet, this resistance was rooted in different views on data governance.

Council 1 had concerns about how personal information was used in projects and how data was released for machine learning (ML) algorithms in terms of definition and scope, which resulted in resistance to sharing data, and therefore in a lack of data availability in the first stages of the project. "Data controllers" within council 1 were resistant to sharing large amounts of training data, and often released datasets that contained a narrow list of variables, with nonindividual level identifiable aggregates, in order to comply with data governance privacy concerns enforced by the data governance team. Their privacy concerns were ultimately related to transparency, bias, and ethics. An academic recalled, "they kept coming back and saying "we need to get approval for this from [data governance team] [who has] a duty to basically ensure data is shared safely with third party organizations." The problem was that "the council used that as an excuse not to share data." A respondent from council 1 added that "first of all, people tend to be default nervous about sharing data. That may stem from just not having a full understanding of data protection and governance." For instance, "at [council 1] they are very wary of anything that would allow anybody not at their premises and not part of their institution to access any sensitive data, even it is anonymized; even if it is structured in ways which would mean it's less sensitive." 
Council 2 was concerned about how personal information was protected when shared with the university. Council 2 leadership expressed concerns about cybersecurity in lieu of current events, "even so this is a contentious issue; we don't want something blowing up in the news like the Cambridge Analytica and everyone suddenly saying, 'oh my goodness what are we doing?!"' Several interviewees from units within council 2 also emphasized that a lot of the data needed for ML "is acutely sensitive, describing in detail some fairly upsetting situations for children we look after", so ensuring the data left organizations in a secure manner was a crucial aspect of the data sharing process for this council.

\section{Routine for addressing data privacy/security concerns: On-site work days and showing the benefits of data sharing}

At council 2, data availability challenges related to cybersecurity were overcome by building trust at the individual level through the creation of a co-location routine, in which academics worked at council 2 with participants "on-site" at least once a week in order to access the organizational data. Describing this routine, one academic respondent said, "by having staff colocated there — because we are available at their offices, they can come to us and ask questions... Our staff are there every week", and another, "on Wednesdays I work at [council 2] and interact with everyone I've done projects with, which was helpful because I could go directly to them if I wanted any clarification." From council 2's perspective, co-location was a beneficial routine because,

"The fact that the researchers come here to our building and sit with use for a whole day....they are there to have some of those conversations and that cross-over of skills and ideas. They become part of the team. And that makes people feel engaged with it all." 
Overall, trust built through face-to-face interaction at council 2 enabled data sharing. In addition, efforts on-site were made that allowed academics to obtain "access to [council 2] hardware; to laptops; so that we [could] access data, work on projects, and deliver something useful." Once trust was built over time during on-site work days, knowledge transfer began to take place as academics could access what they needed to enable ML techniques, enhance organizational capacity, and train government staff. Interestingly, the routine of using "on-site" work days was not implemented in council 1, and council 1 organizations experienced a longer time lag in terms of data resistance and availability issues.

While there was no single routine that directly emerged to alleviate data governance concerns in council 1, communicating the benefits for sharing data for each organization seemed to limit organizational resistance. As stated, "the more evidence you can provide the happier people are. It is something we should be doing all the time." Specifically, that, "organizations are not prepared to give up their data unless they are really clear about what they are going to give up and why." Elaborating on this sentiment, "information sharing projects will always be set up in such a way that you may only use their kind of data for the specific reasons." Eventually, project leadership realized that showing organizations specific areas where they would benefit from the AI methods by sharing data contributed to an easier time with the knowledge transfer process.

\section{Challenge 2: Lack of understanding of what data was available/needed}

The lack of understanding of what data was needed for AI projects also hindered data sharing. Further, for data sharing to happen, organizations had to first understand the nature of the needed data. For example, one interviewee shared that the 
"University needed to understand what was happening and then say 'this is what we could offer to enhance this/to help you.' It was often up to us, [council 1], to say what we wanted them to do. And I think that was the wrong way around."

A similar sentiment was expressed by an individual in council 2, "we had started off thinking, 'ah, so here's some problems which would be well addressed by predictive modeling,' rather than saying, 'what problems is the organization facing? And how can we apply more advanced analytical thinking to that?" In the beginning of the project development, leadership's attention commonly focused on the actions that could be taken with AI to solve problems, rather than thinking about the problems themselves and then what AI solutions were most relevant. The sequencing of the problem-action-analysis was overlooked.

\section{Routine for addressing the lack of understanding about data needs: Re-frame problems}

Because of confusion in both councils over the initial nature driving data sharing, the main way collaborators overcame this challenge was by re-assessing what actions they were hoping to take with AI solutions, as this determined the analysis that had to be executed, and thus the way the data had to be shared. One routine consisted of discussion and brainstorming sessions where the focus was on framing the nature of organizational problems that AI needed to address, instead of starting with what method might be most interesting to use. This is because, as one interviewee said, by first centering around the problems themselves then "we aren't bound by solutions that then have to work." One of the academics shared insights about going back to sequencing needed for data sharing, in that 
“You've just got to start with: 'what's your problem?' and 'how can I solve it?' and get to a common set of problems. If people feel like they are handing over the data and not getting problems solved they are going to be slower to do it."

Focusing on the sequence of defining organization problems and then searching for appropriate AI solutions to use allowed for a better integration of datasets. For example, an academic stated that,

"I think our discourse with [council 2]—we have gotten them to explain the issues. And then we sort of have a process where we get them to define the scope of what it is they want to achieve. We can align our academic outputs from that because we make an assessment: 'Well, is this something that just helps them to do the analysis work?'” Hence, through routinizing opportunities that allowed collaborators to constructively frame their organizational problems, academics were better able to fill the skills and capacities gap for knowledge transfer, which resulting in more willingness to share data.

\section{Challenge 3: Alignment of project interests and expectations around data sharing}

There were also several organizational factors that prevented the formation of expectations and alignment of project interests around sharing data between the university and public organizations. In the beginning, academics had trouble coordinating project expectations because of the large size of council 1, which made navigation, communication, and assigning responsibility for collaborative projects tedious for university partners. Second, in both councils, it was initially difficult to share information between partners effectively to understand different interests. In terms of size, council 2 is "smaller [and] easier to prove who has done what... to 
attribute responsibility, blame, praise, and credit". However, council 1 is "monolithic" and "enormous" in size.

"You've got a massive circle with 4,000 staff in it which is run by an operational director who is driven by a set of legislative and operational constraints which are huge. Whereby the fact that the CF program might be engaging with funky circles who think it's wonderful and everything else...does not mean they really relate to each other very much at all."

In addition, we were told, “you can't really make organizational differences match; what happened was with over a period of time, we found academics that already had an interest with something that matched to a degree things that councils wanted to do", and also, "you had to find a match between the right interests, and for the councils to have the right focus in the particular area" because it is "very much about matching rather than making them come together in any artificial way." At the organizational level, disconnections between project interests and expectations towards data sharing efforts began to resolve when formal navigation approaches and ways to create specific collaborative tasks were applied to council 1.

\section{Routines for aligning project interests and expectations around data sharing (council 1): Designate champions and boundary spanners}

Once project leadership designated formal mechanisms related to role clarity and navigation, which helped academics more effectively engage with the appropriate government staff, it was easier to align interests and stabilize the data sharing process and ensure knowledge transfer. One respondent put it like this, "what happened was with over a period of time, we found academics that already had an interest with something that matched to a degree things that councils wanted 
to do." And also, “some of these risk modeling projects we've been doing with collaborative data have needed really strong project management. They have been critical with setting up those discussions to sell the concepts - that we want to use the data in doing this type of thing." One routine that emerged to help with this challenge with council 1 was the creation of a joint appointment of the role of a Chief Scientific Advisor, which designated a formal position for someone who had both the technical academic knowledge to understand AI as well as public organizational realities. As one participant noted, the joint appointment resulted in more openness between the university and councils: "the fact that the council has been open to [the joint appointment] role and they have been working together to develop his program speaks volumes." Another respondent from the university remarked that, "I think we should've gotten someone on site [at council 1] sooner than we did with a tech background." Another routine that helped project leadership better understand organizational needs and differences in such a large council was to create additional boundary spanners to coordinate information and tasks between partners. "I think once we got people in new roles with the clarity as to what their responsibilities and involvement in the partnership were, then it has been very productive. We have two people at [council 1] now who are coming to regular meetings with the chief data scientist."

\section{Challenge 4: Differences in expectations of top versus bottom within each organization}

At the top level of leadership in council 1, the sentiment was that "there was the belief that [council 1] had signed up to something as had the university; but fundamentally, the people who actually did the stuff with the data probably hadn't signed up to it in the beginning." Elaborating further on this challenge of cohesion and fragmentation, one participant said that:

"I think that the resistance may have come because maybe it was decided by someone at the senior management level who had agreed to something. But then when it comes down 
to the people who are actually doing the analysis in there and the analytical team... they probably haven't had a say in it."

There were also issues about the sense mutual dependencies between the university and councils. "From our side, we were never really clear about what capability the university had." Because there wasn't a consensus about joint dependencies in council 1, for example, initiating collaborative efforts for AI projects, which required cooperating with bottom level "data owners" and analysts, consequently incurred inertia. An analyst from council 1 further described the situation: "I became involved in the projects mostly after the priorities had already been set" and another said, “maybe the core experts of people doing the analysis aren't in the ring, so maybe there is a discrepancy between what will be useful and possible." Even in the beginning, in council 2, the interdependency between the university and the council wasn't always clear for all participants. At first, "it was more of what can we do with it? sort of thinking rather than going to senior management and senior service managers and asking them if we had this ability, what are your priorities for doing things with it etc.” Moreover, council 2 leadership also acknowledged the importance of inclusion in setting AI project priorities because "if you don't have all those people there wanting it, it is very difficult to get anywhere at all."

\section{Routines for achieving cohesion: Connect with all levels of collaborative participants in AI project design and purpose}

Breakthroughs in both councils occurred when all levels of project participants began to feel a connection to the collaborative projects and better understand the capabilities the university could contribute. For both organizations, routinizing ways to showcase the work of potential projects and to showcase the skills academics possess helped overcome disconnection amongst 
collaborative members. The first example of a routine for showcasing work at council 1 was when leadership was able to step back and create dialogue and situations for engagement with analysts that allowed them to clearly see what contributions the university could make:

"Once they saw some of the work the university [did], it was helpful in shifting cooperation. Some of the modeling [academics] did for the data analytics was good, and actually, we thought, 'That's a model we can use!'”.

Project leadership needed to focus on routinizing situations where analysts' confidence could be built incrementally like, "doing test cases; showing what you can do- taking it one step at a time." At council 2, similar routines were less about showcasing the skills, and more focused on showcasing the work of potential successful AI projects to participants. Creating reports and allowing members to see the potential ways AI can help them address the council's problems was helpful. For instance, a manager at council 2 recalls,

"We gave the project team a data set that had some real value and allowed them to test out some theories too. [The academics] provided data analysis to the questions we've raised. The whole thing was very compelling in the end."

Another helpful approach was about showcasing examples that can "help the service deal with things that are relevant to them." A council 2 participant elaborates that when project members regularly met to "underst[and] more of the process; question it; ha[ve] those open conversations that get you to a better end result—without saying why you're doing it, what's your starting point, what's your end point and working through the process... I could be asking completely the wrong thing." 


\section{DISCUSSION}

Our first research question aimed to understand what challenges influence interorganizational projects aimed at $\mathrm{AI}$ adoption. Our findings make two important contributions. First, they show that resistance to sharing data, particularly in the development and adoption stages of AI tools, is the main barrier to the adoption of AI, which is consistent with previous literature on organizational challenges of AI (Sun \& Medaglia, 2019; Christodoulou et al., 2018). Interestingly, other types of challenges seem to influence resistance to share the data.

On the one hand, ethical challenges were considered by both councils. Council 1 was particularly concerned about the use of shared data while council 2 focused on how the data was shared to avoid the disclosure of sensitive information to the public. On the other hand, data challenges, and particularly privacy and security issues, were also taken into account by both councils, yet differently and depending on their diverse interpretations of the DPA/GDPR requirements. Finally, additional organizational challenges, such as the tension between the need to share the data and the interests and expectations of individual organizations and the lack of implementation guidelines for those in charge of executing top managers decisions, also resulted in resistance to share the data. Although the literature has referred to all these types of challenges in the adoption of AI (e.g. Wirtz et al., 2019; Sun \& Medaglia, 2019; Wirtz \& Müller, 2019; Dwivedi et al., 2019; Krishnamurthy \& Desouza, 2018; Mehr, 2017; Janssen \& Kuk, 2016), our findings further indicate that the relationship between each of these categories of challenges and adoption of AI is not unilateral. Instead, different types of challenges combine and amplify each other (Gil-Garcia \& Sayogo, 2016), resulting in additional challenges (in our case, resistance to share the data, an organizational challenge) that influence adoption. 
Second, our results place greater emphasis on data challenges than previous studies on digital government (e.g. Jimenez \& Gasco, 2011), which seems to confirm that the nature of AI projects make these type of factors particularly relevant (Kankanhalli et al., 2019; Sun \& Medaglia, 2019; Desouza \& Jacob, 2017; Krishnamurthy \& Desouza, 2014).

The second research question of our study aimed at identifying the organizational routines that managers perform to overcome challenges. These organizational routines varied across councils and included working on-site, showing the benefits of data sharing, re-framing problems, designating joint appointments and boundary spanners, and connecting all levels of collaborative participants around project design and purpose. Generally speaking, our results show that the adoption of $\mathrm{AI}$ in public sector organizations requires customizable, multi-strategy approaches to shaping effective data sharing in which actors adapt their organizational routines in response to feedback from different learning processes (Raub \& Von Wittich, 2004; Feldman $\&$ Pentland, 2003). There is, therefore, no one-size-fits-all approach to a successful adoption. Further, our findings indicate that, despite the existence of different types of challenges, the emphasis on improving organizational processes is key to overcome them (e.g., privacy and security concerns were not addressed with more data privacy and security practices, but with routines aimed at increasing trust and showing the benefits of the data).

Some additional observations can be made regarding specific organizational routines. First, our findings indicate that building trust is a requirement for a successful practitionerscholar collaboration (Kankanhalli et al., 2019; Mikhaylov et al., 2018; Yang \& Maxwell, 2011). In particular, our study is in line with previous findings in the literature on collaboration and shows that face-to-face interaction helps build trust and that the creation of learning spaces is a successful management activity for overcoming institutional differences between participants in 
interorganizational projects (e.g. Vangen, 2017). Indeed, the social interaction and the informal relationships that arose in these spaces among the staff of different organizations were beneficial to align expectations and build trust, resulting in data sharing. As Willem and Buelens (2007) indicate, this routine seemed suitable given the bureaucratic nature of the two councils, which could have slowed down the process if more formal mechanisms had been used (Amayah, 2013). Interestingly enough, our findings do not resonate with recent studies that state that technology has the capacity to strengthen interorganizational collaboration (e.g. Livermore \& Verbovaya, 2016), which may indicate that in complex projects, such as AI ones, the face-to-face component becomes key.

Second, clarifying roles and responsibilities in the collaboration (for example, as is the case here, by appointing champions) and showing the benefits of the project, and therefore of sharing the data, seem to be successful organizational routines to also overcome distrust. Our results therefore confirm some of the most successful strategies already addressed by previous studies on digital government, knowledge transfer and collaboration (e.g. Cristofoli et al., 2015; Amayah, 2013; Pardo et al., 2012; Willem \& Buelens, 2007; Ansell \& Gash, 2008; Vangen \& Huxham, 2003).

Finally, our findings also indicate that engagement and participation across the organization is important for project success. Further, in line with Saz-Carranza \& Ospina (2010), our results show that engagement should happen from the very beginning, as was the case in council 2, so tensions can be addressed and basic agreements and procedures set up for project success early in the process (Ansell \& Gash, 2008). Nevertheless, we argue that in AI projects, the organizational routine of connecting members across the organization is even more important given the different profiles of those involved in the collaboration (Sun \& Medaglia, 
2019). Thus, although the councils' leadership understood the strategic direction of the project, it was important for data analysts and academics to showcase their work using AI methods to be able to better understand the potential of the project.

\section{CONCLUSIONS}

The goal of this research was to study the challenges of interorganizational collaborations in the different stages of AI adoption and the implementation of organizational routines used to address those challenges. We conclude that several of our findings are in line with current studies of AI in the public sector as well as with previous literature on digital government, cross-sector collaboration, and knowledge transfer. The latter makes sense given that, in nature, AI projects are technological, collaborative, and based on heavy data sharing. There is, therefore, no need to reinvent the wheel when assessing challenges and evaluating successful organizational routines to address them.

However, we have also identified certain elements that seem to be specific to these types of projects and that should, therefore, be addressed in future studies to gather more empirical evidence in this respect. First, although data challenges are not new in the literature, they seem to be particularly relevant in AI projects given the risks associated to these projects, especially in terms of privacy and security, and the volume of data that is required to be shared to create effective algorithms. Second, it is actually the combination of different types of challenges, which reinforce each other, which results in resistance to share the data, compromising the adoption of AI projects. More quantitative and qualitative research could look at the specific interactions among challenges and, therefore, at their direct and indirect effect on the adoption of AI. 
Third, despite the entanglement of different challenges, successful organizational routines were mainly about improving organizational practices. We argue that, given the complexity of AI projects, further research should focus on how specific organizational routines, which have received minimal attention in the $\mathrm{AI}$ adoption debate so far, may be useful to address organizational but, also, other types of challenges. In particular, additional studies could address the discrepancies between top managers (the decision makers, who usually have little knowledge on the specificities of $\mathrm{AI}$ ) and the implementers (the $\mathrm{AI}$ experts and specialists).

Finally, our study is not without limitations. In particular, the context of the study (collaborative AI projects in England between two councils and a university) and the qualitative approach used may limit the generalizability of our results. Nonetheless, we believe our research generates interesting results and further stimulates the conversation about AI adoption in the public sector.

\section{REFERENCES}

Agarwal, P. K. (2018). Public administration challenges in the world of AI and bots. Public Administration Review, 78(6), 917-921.

Agranoff, R. (2006). Inside collaborative networks: Ten lessons for public managers. Public Administration Review, 66(Special Issue), 56-65.

Alberti, I. (2018). Artificial intelligence in the public sector: Opportunities and challenges. $1^{\text {st }}$ Edition of the Seminars of the PhD School in Public, International and European Union Law of Università degli Studi di Milano. Gargnano (Italy), October $15^{\text {th }}-17^{\text {th }}$.

Amayah, A. (2013). Determinants of knowledge sharing in a public sector organization. Journal of Knowledge Management, 17(3), 454-471. 
Andrews, L. (2019). Public administration, public leadership and the construction of public value in the age of the algorithm and 'big data'. Public Administration, 97(2), 296-310.

Ansell, C. \& Gash, A. (2008). Collaborative governance in theory and practice. Journal of Public Administration Research and Theory, 18(4), 543-571.

Bernard, H. R. (2017). Research Methods in Anthropology: Qualitative and Quantitative Approaches. Oxford: Rowman \& Littlefield.

Bullock, J. (2019). Artificial intelligence, discretion, and bureaucracy. American Review of Public Administration, 49(7), 751-761.

Charmaz, K. (2014). Constructing Grounded Theory. London: SAGE.

Chen, Y. \& Lee, J. (2017). Collaborative data networks for public service: Governance, management, and performance. Public Management Review, 20(5), 672-690.

Cristofoli, D., Maccio, L., Pedrazzi, L. (2015). Structure, mechanisms, and managers in successful networks. Public Management Review, 17(4), 489-516.

Christodoulou, P., Decker, S., Douka, A.-V., Komopoulou, C., Peristeras, V., Sgagia, S., Tsarapatsanis, V. \& Vardouniotis, D. (2018). Da makes the public sector go round. International Conference on Electronic Government (EGOV) 2018. Krems (Austria), September $3^{\text {rd }}-5^{\text {th }}$.

Desouza, K. (2018). Delivering artificial intelligence in government: Challenges and opportunities. Washington DC: IBM Center for the Business of Government.

Desouza, K. \& Jacob, B. (2017). Big data in the public sector: Lessons for practitioners and scholars. Administration \& Society, 49(7), 1043-1064.

Dwivedi, Y. K., Hughes, L., Ismagilova, E. et al (2019). Artificial Intelligence (AI): Multidisciplinary perspectives on emerging challenges, opportunities, and agenda for 
research, practice and policy. International Journal of Information Management, available online.

Duan, Y., Edwards, J. \& Dwivedi, Y. (2019). Artificial intelligence for decision making in the era of big data - Evolution, challenges and research agenda. International Journal of Information Management, 48(October), 63-71.

European Commission (2019). A definition of AI: Main capabilities and scientific disciplines. Brussels: High-Level Expert Group on Artificial Intelligence.

Feldman, M. S., \& Pentland B. T. (2003). Reconceptualizing organizational routines as a source of flexibility and change. Administrative Science Quarterly, 48, 94-118.

Freeman, D., Ho, D., Sharkey, C. \& Cuella, M-F. (2020). Government by algorithm: Artificial intelligence in federal administrative agencies. Washington DC: Administrative Conference of the United States.

Gasco, M. \& Jimenez, C. (2011). Interoperability in the justice field: Variables that affect implementation. $11^{\text {th }}$ European Conference on E-Government - ECEG 2011. University of Ljubljana. Ljubljana (Slovenia), June $16^{\text {th }}{ }_{-17 \text { th }}$.

Gil-Garcia, J. R. \& Sayogo, D. S. (2016). Government inter-organizational information sharing initiatives: Understanding the main determinants of success. Government Information Quarterly, 33(3), 572-582.

Gomes de Sousa, W., Pereira de Melo, E. R., De Souza Bermejo, P. H., Souza Farias, R. A. \& Oliveira Gomes, A. (2019). How and where is artificial intelligence in the public sector going? A literature review and research agenda. Government Information Quarterly, 36(4), 101392. 
Halcomb, E. \& Davidson, P. (2006). Is verbatim transcription of interview data always necessary? Applied Nursing Research, 19(1), 38-42.

Ishii, K. (2017). Comparative legal study on privacy and personal data protection for robots equipped with artificial intelligence: Looking at functional and technological aspects. $A I \&$ Society, 34, 509-533.

Janssen, M. \& Kuk, G. (2016). The challenges and limits of big data algorithms in technocratic governance. Government Information Quarterly, 33(4), 371-377.

Jordan, M. I. (2019). Artificial intelligence - The revolution hasn't happened yet. Harvard Data Science Review, June.

Kankanhalli, A., Charalabidis, Y. \& Mellouli, S. (2019). IoT and AI for smart government: A research agenda. Government Information Quarterly, 36(2), 304-309.

Kim, Y. \& Crowston, K. (2012). Technology adoption and use theory review for studying scientists' continued use of cyber-infrastructure. Proceedings of the American Society for Information Science and Technology, 48(1), 1-10.

Korinek, A. \& Stiglitz, J. (2017). Artificial intelligence and its implications for income distribution and inequality. Working Paper 24174. Cambridge, MA: National Bureau of Economic Research.

Krishnamurthy, R. \& Desouza; K. (2014). Big data analytics: The case of the social security administration. Information Polity, 19(3), 165-178.

Lee, D., McGuire, M., Kim, J. (2018). Collaboration, strategic plans, and government performance: the case of efforts to reduce homelessness. Public Management Review, $20(3), 360-376$. 
Livermore, M. \& Verbovaya, O. (2016). Doing collaboration: how organizations use Facebook to foster collaboration. Human Service Organizations: Management, Leadership \& Governance, 40(5), 553-571.

Marshall, G. B. C. \& Rossman (2011). Designing qualitative research. Thousand Oaks, CA: SAGE Publications.

Mehr, H. (2017). Artificial intelligence for citizen services and government. Cambridge, MA: Harvard Kennedy School - Ash Center for Democratic Governance and Innovation.

Mikhaylov, S. J., Esteve, M., \& Campion, A. (2018). Artificial intelligence for the public sector: Opportunities and challenges of cross-sector collaboration. Philosophical Transactions of the Royal Society A: Mathematical, Physical and Engineering Sciences, 376(2128), 20170357.

Ospina S, Esteve M \& Seulki L. (2018). Assessing Qualitative Studies in Public Management Research. Public Administration Review, 78(4), 593-605.

Pardo, T., Nam, T. \& Burke, B. (2012). E-government interoperability: Interaction of policy, management, and technology dimensions. Social Science Computer Review, 30(1), 7-23.

Patton, M. (2002). Two decades of developments in qualitative inquiry: A personal, experiential perspective. Qualitative Social Work, 1(3), 261-283.

Pentland, B., M. S., Feldman (2005). Organizational routines as a unit of analysis. Industrial and Corporate Change, 14(5), 793-815.

Raub, S. \& Von Wittich, D. (2004). Implementing knowledge management: Three strategies for effective CKOs. European Management Journal, 22(6), 714-724.

Risse, M. (2019). Human rights and artificial intelligence: An urgently needed agenda. Human Rights Quarterly, 41(1), 1-16 
Saz-Carranza, A. \& Ospina, S. (2010). The behavioral dimension of governing interorganizational goal-directed networks. Managing the unity-diversity tension. Journal of Public Administration and Theory, 21(2), 327-365.

Sun, T. Q. \& Medaglia, R. (2019). Mapping the challenges of artificial intelligence in the public sector: evidence from public healthcare. Government Information Quarterly, 36(2), 368383.

Vangen, S., Huxham, C. (2003). Nurturing collaborative relations: building trust in interorganizational collaboration. The Journal of Applied Behavioral Science, 39(1), 5-31.

Vangen, S. (2017). Culturally diverse collaborations: A focus on communication and shared understanding. Public Management Review, 19(3), 305-325.

Veale, M., Van Kleek, M. \& Binns, R. (2018). Fairness and accountability design needs for algorithmic support in high-stakes public sector decision-making. 2018 CHI Conference on Human Factors in Computing Systems (CHI'18). Montreal (Canada), April $21^{\text {st }}-26^{\text {th }}$.

Willem, A. \& Buelens, M. (2007). Knowledge sharing in public sector organizations: The effect of organizational characteristics on interdepartmental knowledge sharing. Journal of Public Administration Research and Theory, 17(4), 581-606.

Wirtz, B. \& Müller, W. (2019). An integrated artificial intelligence framework for public management. Public Management Review, 21(7), 1076-1100.

Wirtz, B., Weyerer, J., Geyer, C. (2019). Artificial intelligence and the public sectorApplications and challenges. International Journal of Public Administration, 42(7), 596615. 
Yang, T.-M. \& Maxwell, T. (2011). Information-sharing in public organizations: A literature review of interpersonal, intra-organizational and inter-organizational success factors. Government Information Quarterly, 28(2), 164-175.

Yin, R. K. (2013). Case study research: Design and methods. Thousand Oaks, CA: SAGE. 